\title{
Numerical Simulation and Analysis on the Instability and Deformation of the L245/316L Bimetallic Clad Tube Liner
}

\author{
Zhao Yufei ${ }^{1,2, ~ *, ~ H a n ~ W e n l i ~}{ }^{1,2}$, Zhou Bing ${ }^{1,2}$, Zhang Yingying ${ }^{1,2}$, Guo Jiyin ${ }^{1,2}$, Zhang Yanjun ${ }^{1,2}$ \\ ${ }^{1}$ CNPC Research Institute of Engineering Technology, Tianjin, China \\ ${ }^{2}$ Key Laboratory of Tubular Goods Engineering, CNPC-Research Division of Anti-Corrosion Coating and Thermal Insulation Structure, \\ Tianjin, China
}

Email address:

Zhayf16@cnpc.com.cn (Zhao Yufei),hanwl@cnpc.com.cn (Han Wenli)

${ }^{*}$ Corresponding author

\section{To cite this article:}

Zhao Yufei, Han Wenli, Zhou Bing, Zhang Yingying, Guo Jiyin, Zhang Yanjun. Numerical Simulation and Analysis on the Instability and Deformation of the L245/316L Bimetallic Clad Tube Liner. International Journal of Materials Science and Applications.

Vol. 7, No. 4, 2018, pp. 133-141. doi: 10.11648/j.ijmsa.20180704.13

Received: June 24, 2018; Accepted: July 13, 2018; Published: July 19, 2018

\begin{abstract}
The quality of the L245/316L bimetallic clad tube is greatly decided by the stability of the liner. In this work, the ABAQUS finite element software was used to simulate and analyze the instability and deformation of the L245/316L bimetallic clad tube liner during the coating process under different temperatures and during the compression and depressurization process under the condition that whether there was defect in the substrate and liner. The simulation and analysis results demonstrated that coating under the temperature of $230^{\circ} \mathrm{C}$ could result in the instability deformation of the liner because of the combining effects of thermal expansion and contraction, residual stress and external constraint. In addition, defects between the substrate and liner could lead to the instability deformation of the liner in the compression and depressurization process.
\end{abstract}

Keywords: Numerical Simulation, L245/316L Bimetallic Clad Tube, Instability and Deformation

\section{Introduction}

With the development of the modern petrochemical industry, the requirements for the tube quality are more and more rigor. The tube should have high strength as well as excellent high temperature resistance and corrosion resistance performance [1]. However micro-alloy and heat treatment can improve a certain property of the tube, it can not afford the need of the combination property. The appearance of the bimetallic clad tube consisting of substrate and liner solves the problem. Generally, the substrate uses carbon steel to ensure its excellent mechanical property. The material used for liner is mainly decided on the special property requirements and service environments $[2,3]$.

The L245/316L bimetallic clad tube is one of the most widely used tubular products in the petrochemical industry because of its excellent mechanical property and high temperature resistance and corrosion resistance performance which can significantly prolong the service life of the tube $[4$,
5]. However, during its fabricated process, plastic deformation often appears on the liner and therefore the liner separate from the substrate. The instable deformation can greatly decrease the service life of the bimetallic clad tube [6].

Numerical simulation is an effective way to analyze the instable deformation of the bimetallic clad tube. Alcaraz [7] and Berski [8] simulated the effects of the different technological parameters, the shape of the mould, compressibility and federate to the extrusion forming process of the bimetallic clad tube. Mohebi M S $[9,10]$ investigated the effects of different parameters to the bimetallic clad tube via spin-bonding experiment. Rimma L K [11] obtained the minimum rotating pressure to the spinning manufacture process. $\mathrm{Du}$ [12] investigated the $\mathrm{Al} / \mathrm{Mg}$ bimetallic clad tube extrusion forming process using ABAQUS finite element software and obtained the temperature filed and the distribution of stress and strain of the deformation body. However, there is few investigations on the instable deformation of the L245/316 Limetallic clad tube liner. 
In the present work, the instability and deformation of the L245/316L bimetallic clad tube liner under different temperature coating process and in the pressure and relief process under the condition that whether there was defect between the substrate and liner was simulated and analysed using ABAQUS finite element software. In addition, the simulation results were compared with the practical manufacture process to verify its veracity.

The simulation results have great significances to the practical manufacture process. It shows the effect of temperature and defects on the stability of the liner of the L245/316L bimetallic clad tube which can significantly guide the set of technological parameters in the practical manufacture process improving the quality of the L245/316L bimetallic clad tube.

\section{Experiments}

\subsection{Numerical Simulation}

The numerical simulation was conducted using the FLUENT and ABAQUS finite element software. The simulation process mainly includes modeling, meshing, boundary conditions setting, parameters setting and simulation.

\subsection{Coefficient of Thermal Expansion Test}

The coefficient of thermal expansion test was conducted using the NETZSCH DIL $402 \mathrm{C}$ thermal dilatometer. Heat up to $200^{\circ} \mathrm{C}$ at the speed of $5 \mathrm{~K} / \mathrm{min}$ in the air condition. The results of the transverse stretching distance were real timely measured and recorded. Then the coefficient of thermal expansion was calculated. The samples were cut from the substrate and liner separately and machined to the size of $8 * 8 * 25 \mathrm{~cm}^{3}$. The specimens were carefully grounded and polished. Each edge was chamfered.

\section{Assumptions}

During the simulation process, in order to simplify the model to improve the convergence and the calculation speed, the real force-bear situation is simplified as follows.

(1) Simplify the three-dimension tube to two-dimension section to simulate the deformation during the coating process.

(2) Because the substrate and liner was mechanically joined via explosive welding, plastic deformation occurred in the liner resulting in the residual stress in both substrate and liner. In the simulation process, the initial residual stress was simulated via setting initial pre-stress.

(3) The binding force between the substrate and liner which was $0.4 \mathrm{MPa}$ was equivalent to $0.4 \mathrm{MPa}$-force applied on the inside of the liner.

(4) There was vapor in the interstice between the substrate and liner. The effect of vapor was equivalent to applying different steam stress at different temperature on both the substrate and liner.

\section{Results and Discussion}

\subsection{Simulation of the Coating Process}

The two-dimension tube model coating process was established using the ABAQUS finite element software. The finite element method was used to simulate the coating process under the temperature of both $230^{\circ} \mathrm{C}$ and $180^{\circ} \mathrm{C}$ to analyze the deformation of the liner under the effect of thermal conduction.

The deformation of the L245/316L bimetallic clad tube liner during the heating and cooling process under the temperature of $230^{\circ} \mathrm{C}$ is displayed in Figure 1. Generally, the temperature of the outer substrate has reached the preset value which is $230^{\circ} \mathrm{C}$. While the temperature of the liner firmly bonding with the substrate is pretty high, the temperature of liner separating from the substrate is rather low. As shown in Figure 1, slight plastic deformation can be observed in the upper left area leading to the separation of the substrate and liner. By contrast, serious plastic deformation has formed in the lower right hand of the liner resulting in the instability of the bimetallic clad tube.

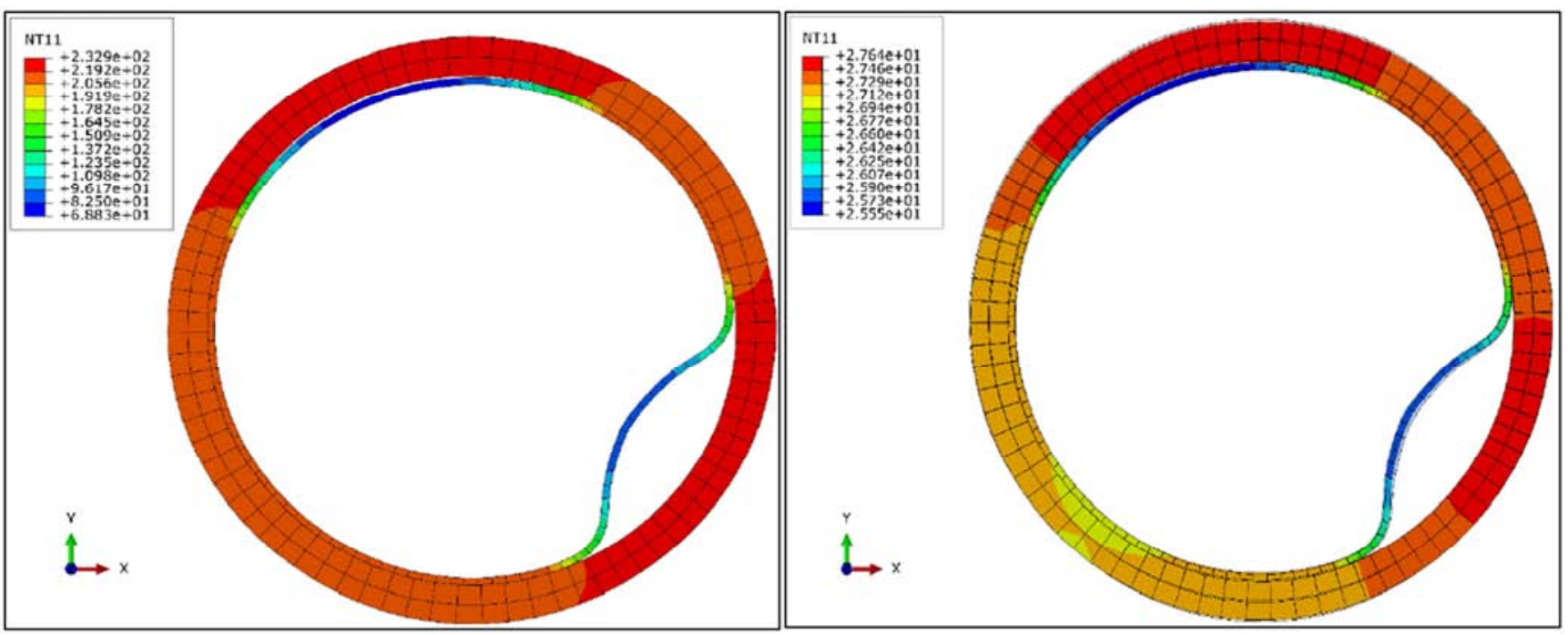

Figure 1. The deformation and temperature cloud chart at the room and high temperature of the $230^{\circ} \mathrm{C}$ coating process. 
It is apparent that the instable deformation is the result of the combining effects of thermal expansion and contraction, residual stress and external constraint. The following described every influencing factor in detail.

(1) The thermal expansion and contraction effect

The coefficient of thermal expansion of the liner is more than twice that of the substrate. During the heating process, if there are interstices between the substrate and liner, heat in the interstice can only transfer via thermal radiation. The firmly bonding area can transfer heat via thermal conduction whose heat transfer efficiency is much higher than thermal radiation. As a result, the temperature of the interstice area is much lower than other areas. While thermal expansion is obvious in the high temperature substrate area, the deformation in the low temperature liner area is rather slow. As a consequence, the liner separates from the substrate because of the difference of the deformation velocity, which is shown in Figure 1.

The air in the interstice and inner of the liner was heat up during the heating stage. In the cooling process, the liner near the interstice need to dissipate thermal via radiation heat transfer with the hot air which is pretty slow. However, the outside of the substrate dissipates thermal directly to the atmosphere, which is much faster than radiation heat transfer. Consequently, in the cooling process, the liner is condensed by the substrate because the cooling shrinkage velocity of the substrate is much faster than that of the liner. Then, plastic deformation happens.

(2) The residual stress

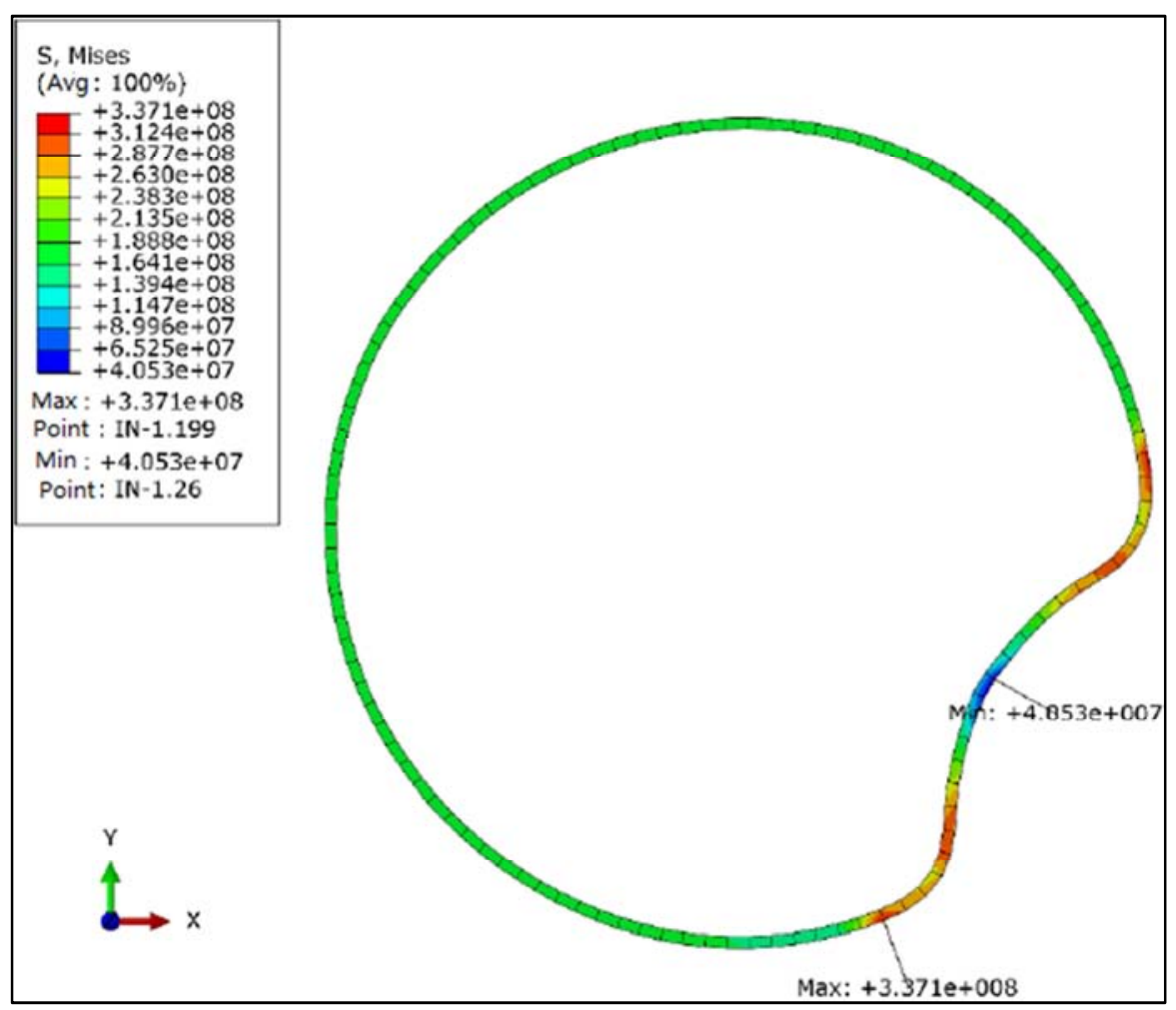

Figure 2. The stress pattern of the liner.

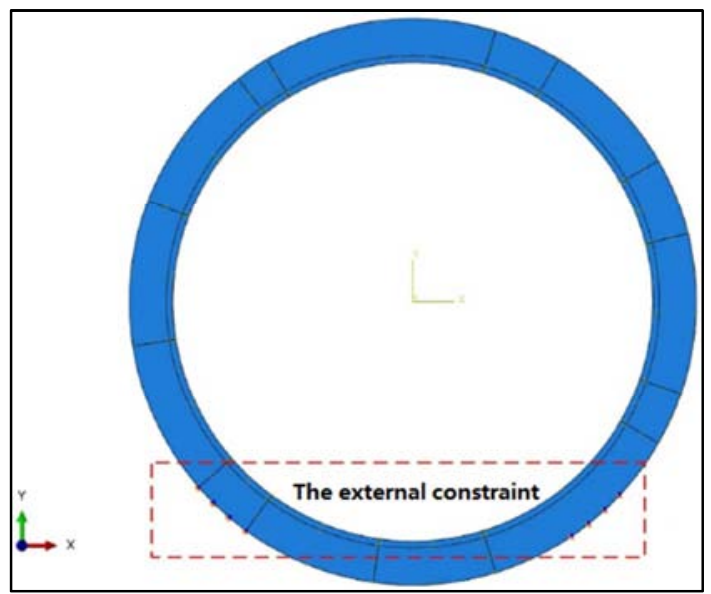

Figure 3. The location of the external constraint.
After explosion welding, there still exits pretty high residual stress in the substrate and liner. With coating process going on, the liner separates from the substrate. Therefore, the constraint applied on the liner becomes smaller. During the heating process, the residual stress releases and deformation appears. Figure 2 presents the stress pattern of the liner. Obviously, the stress of the firmly bonding area still reaches 139 to $160 \mathrm{MPa}$. The minimum of the residual stress which is 4 to $114 \mathrm{MPa}$, appears in the middle of the instable deformation region. It demonstrates that residual stress has released in this area. Generally, residual stress may occur in the whole instable deformation area $[13,14]$. The junction of the stability and instability region is a rather special point. In this point, severe deformation happens that induces strong stress.

(3) The external constraint 
The external constrain points are displayed in Figure 3. As shown in Figure 1, some deformations have appeared in both the upper left and the lower right corner of the liner. Nevertheless, the plastic deformation in the lower right corner is much more severe than that in the upper left corner. It is mainly attributed to that the existence of the external constraint limits the thermal expansion of the substrate in some extent. On the other hand, the thermal expansion of the liner is restricted by the substrate. The deformation can only try to transfer to area without constraint leading to the inward convex of the liner.
Figure 4 shows the deformation of the L245/316L bimetallic clad tube liner during the heating and cooling process under the temperature of $180^{\circ} \mathrm{C}$. Compared with $230^{\circ} \mathrm{C}$ coating process, the thermal expansion under $180^{\circ} \mathrm{C}$ is smaller. During the cooling process, the deformation of the instable area may further develop because of the shrinkage velocity difference between the substrate and liner. Under lower temperature, the effects of the residual tress release and the external constraint is much weaker resulting in smaller instable deformation. As a result, there is no inward convex appear in the liner.

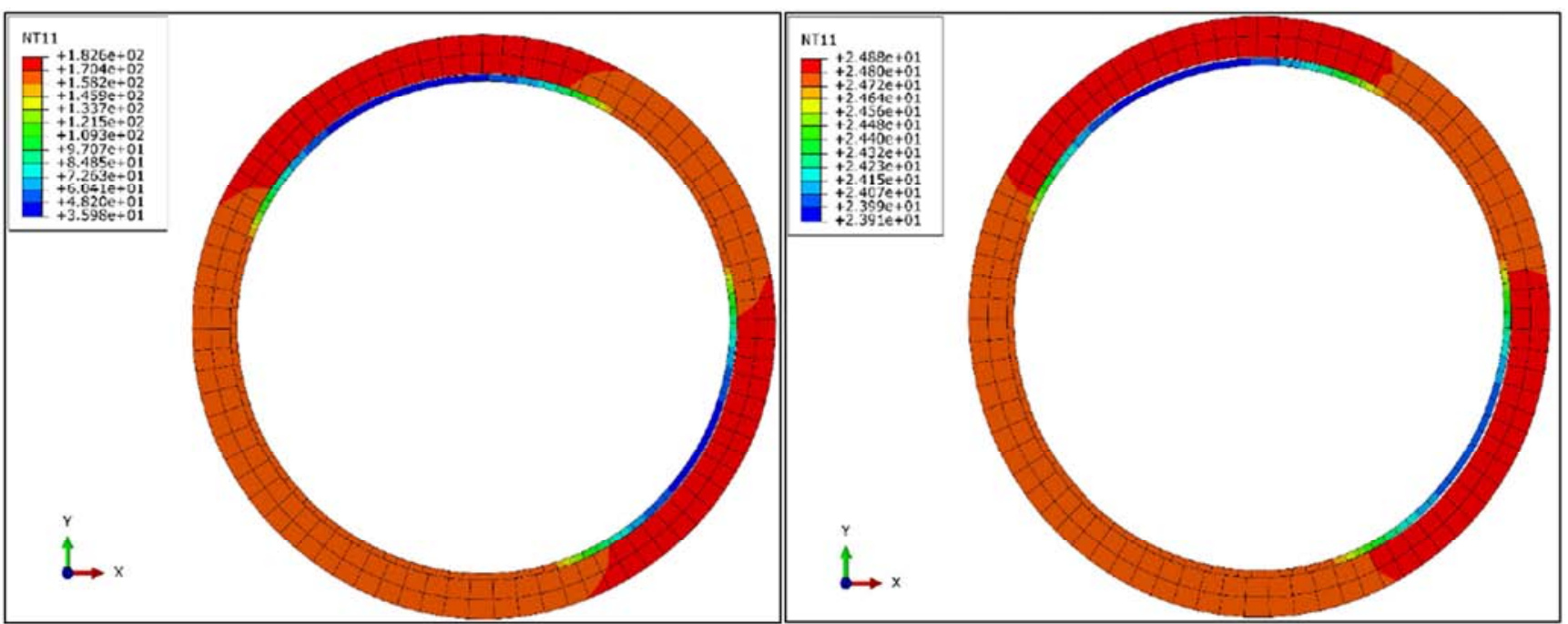

Figure 4. The deformation and temperature cloud chart at the room and high temperature of the $180^{\circ} \mathrm{C}$ coating process.

\subsection{Simulation of the Compression and Depressurization Process}

Extract the instable deformation model which is obtained during the coating process simulation to proceed the simulation of the compression and depressurization process. The load boundary conditions is set as $1.3 \mathrm{MPa} / \mathrm{h}$ compression speed and $1.8 \mathrm{MPa} / \mathrm{h}$ depressurization speed. Considering the change of temperature of the compression and depressurization process, the temperature boundary conditions is also pre-setted. The results of twenty times compression and depressurization process are displayed in Figure 5.

Without the sustainment of the substrate, the instable deformation area of the liner is easy to loss stability during the compression process. The $13 \mathrm{MPa}$ compression pressure can press the plump liner to the substrate again. Therefore, permanent plastic deformation occurs in the liner which can not recover after depressurization process. Different compression and depressurization times have no effect on the liner, so the instable deformation area always keeps the shape after the first compression.

In the practical process, depressurization can lead to negative pressure in the inside of the tube. Under the pressure of the atmosphere, unstable collapse occurred. Considering the effect of the pressure, the compression and depressurization process is also simulated. The two-dimension tube with defects was established using FLUENT software and the change of the pressure of the defects area was analyzed during the compression and depressurization process using finite volume method. The pressure at the Pressure-out is $13 \mathrm{MPa}$ and the depressurization speed is $1.8 \mathrm{MPa} / \mathrm{h}$. The detail boundary conditions are displayed in Figure 6.

The simulation results are presented in Figure 7 . Obviously, great change of pressure appeared in the defect area. In the depressurization process, the negative pressure can reach $3.5 \mathrm{MPa}$ in the defect area. Calculate the different value between the negative and atmosphere pressure and apply it to the ABAQUS established liner model to simulate the suffered force of the liner under the real negative pressure. The results are displayed in Figure 8 . The instable deformation appears in the upper left corner of the liner and the lower right corner is in good condition. It demonstrates that the area where the instable deformation occurs is stochastic. However, it is closely related to the location and length thick ratio of the defect. Large length thick ratio facilitates the occurrence of the instable deformation. 


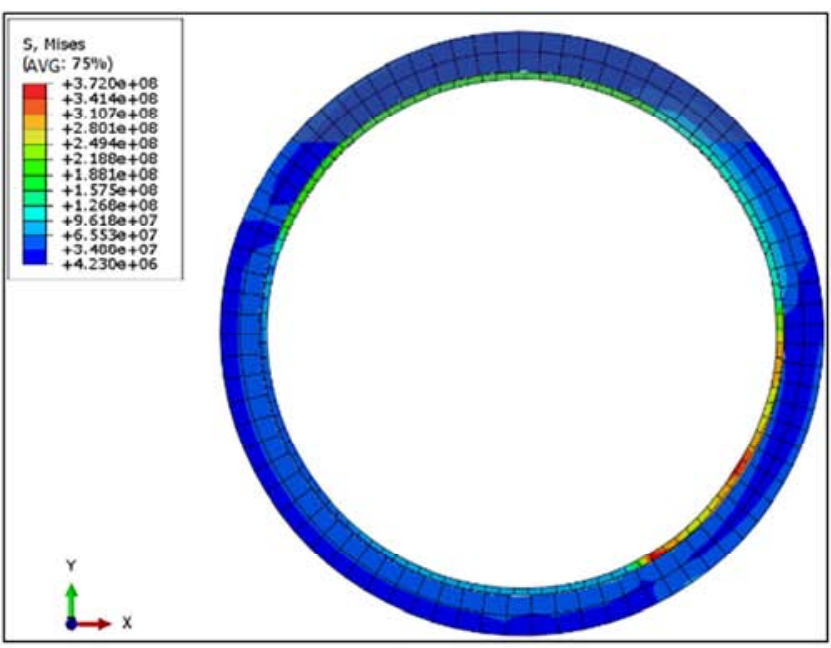

a. Once

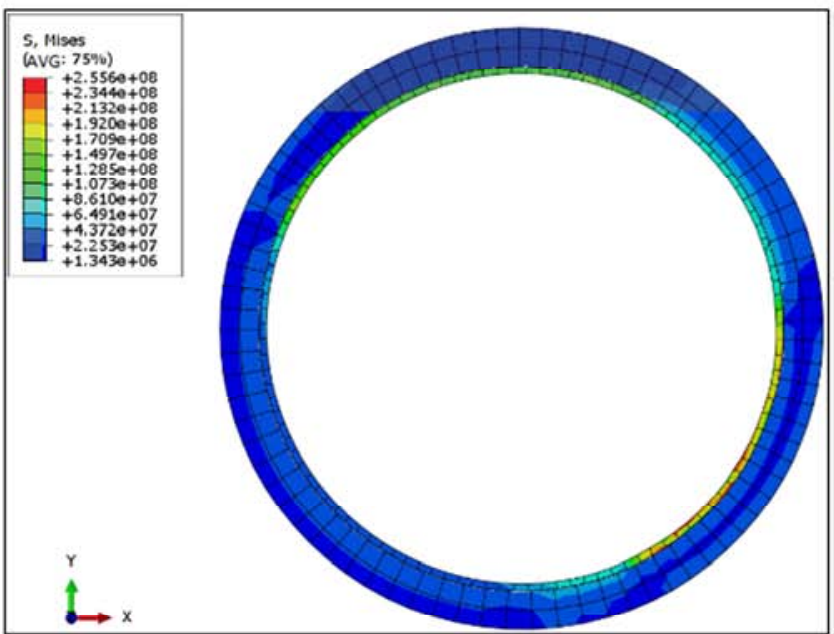

c. Five times

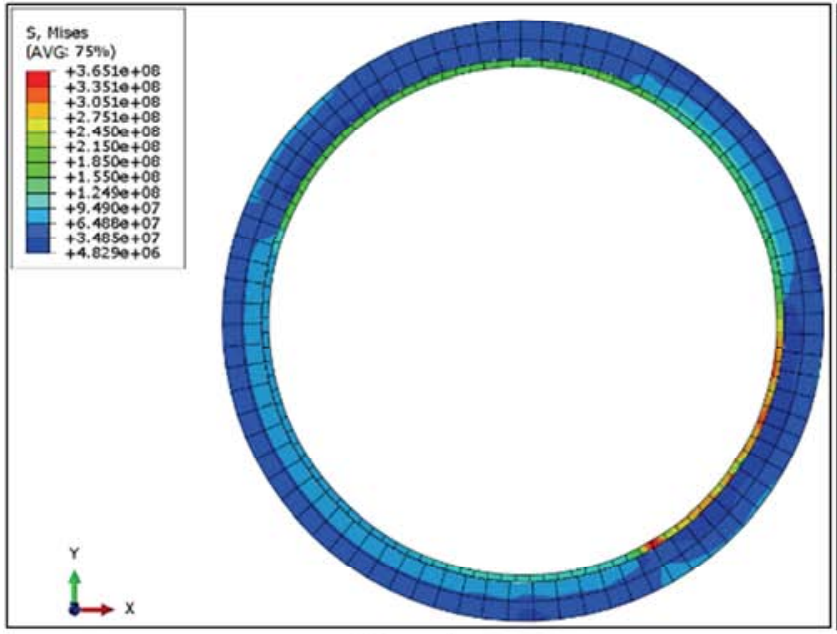

e. Fifteen times

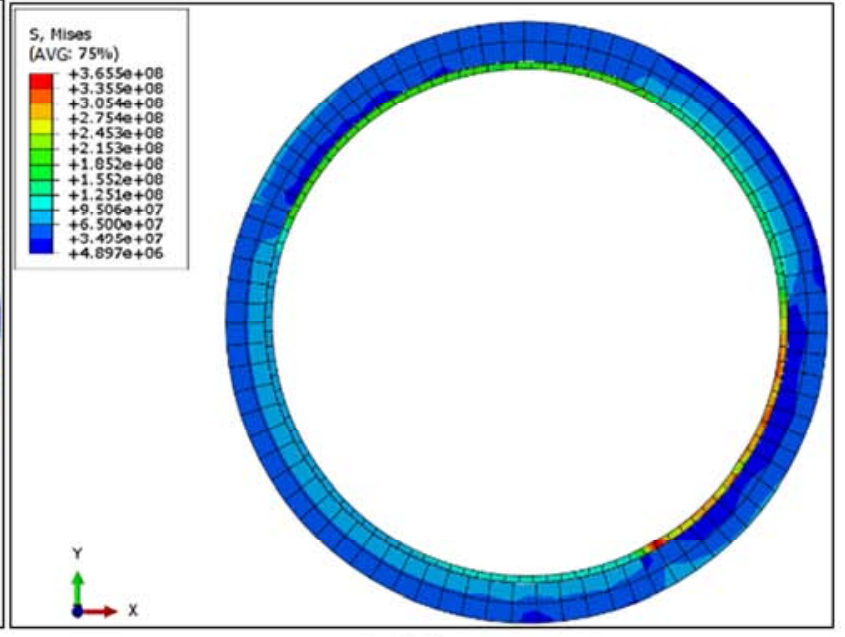

b. Twice

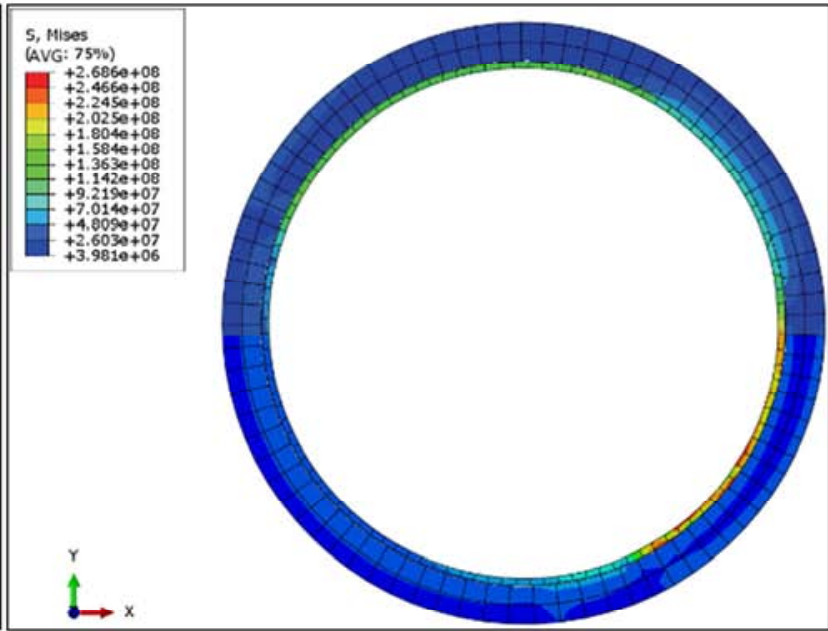

d. Ten times

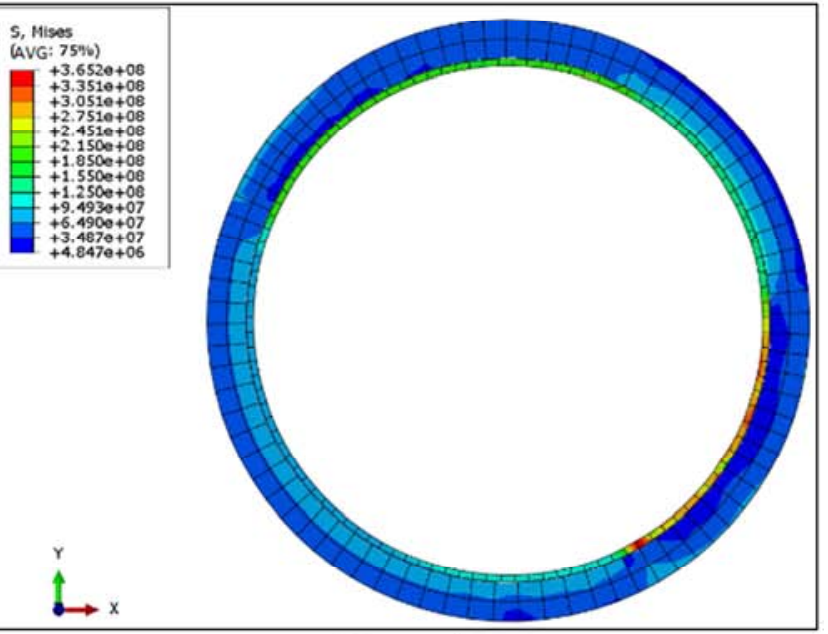

f. Twenty times

Figure 5. The deformation and temperature cloud chart of the bimetallic clad tube after different compression and depressurization times.

Defect2

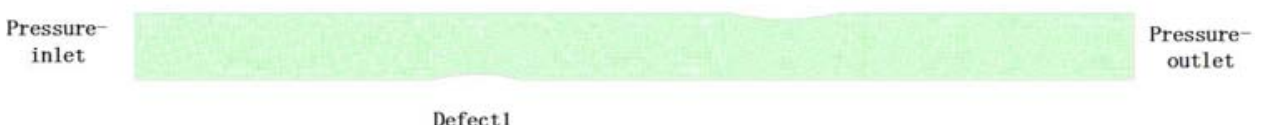

Defect1

Figure 6. The Fluent grid and boundary condition. 


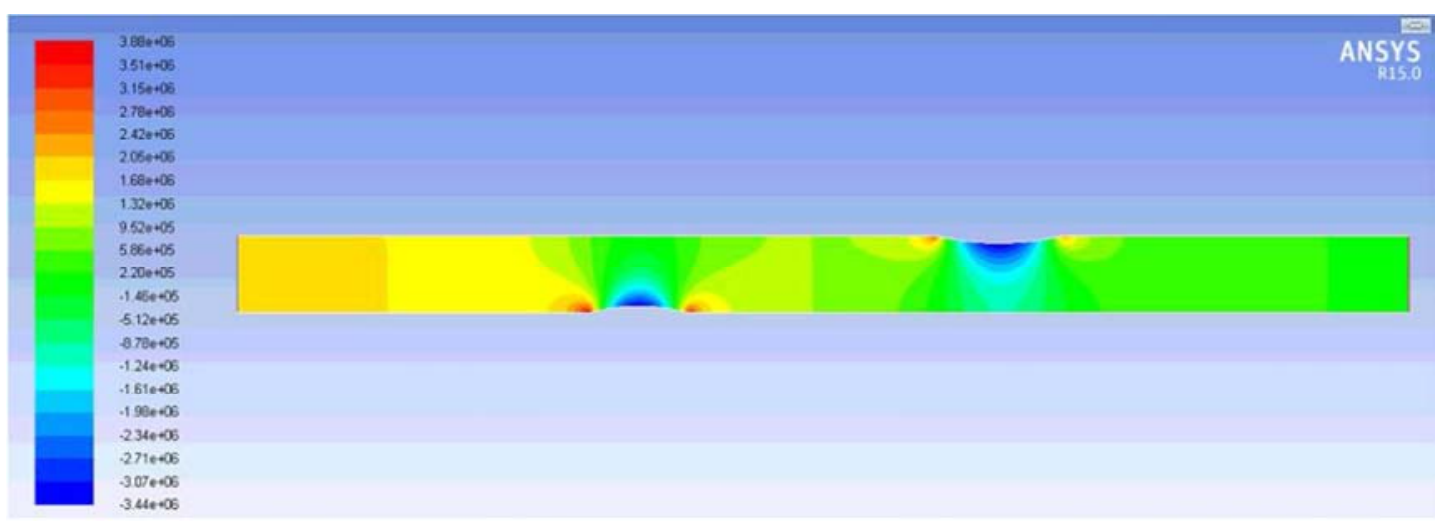

Figure 7. The stress pattern of the bimetallic clad tube with defects.
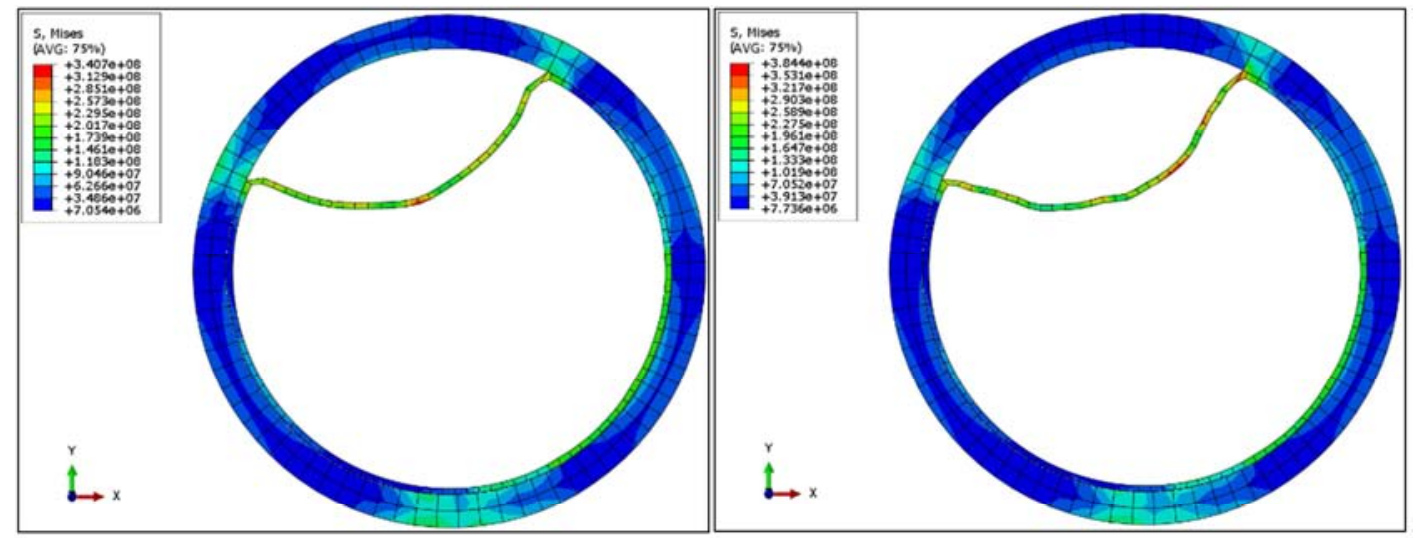

a. Once
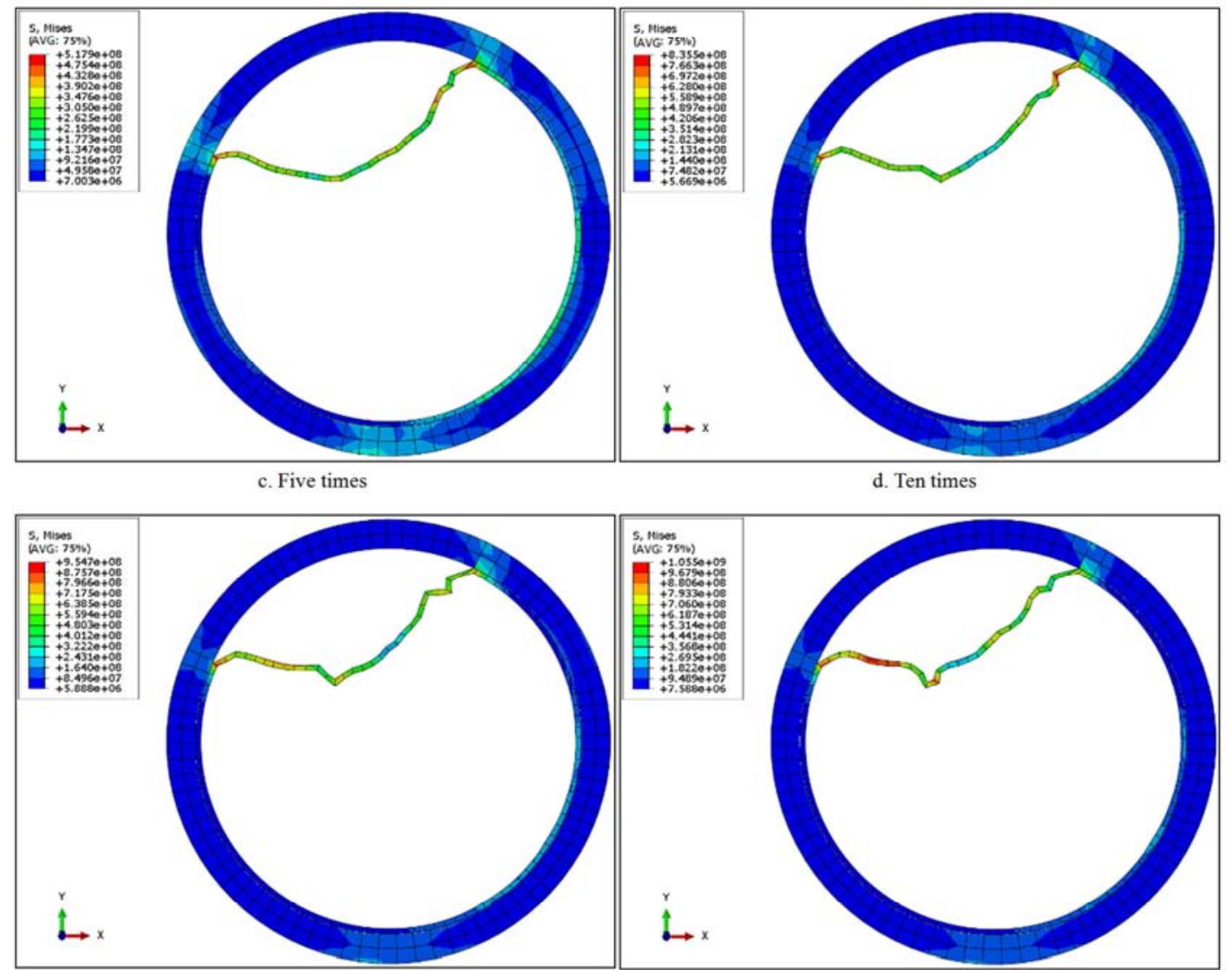

e. Fifteen times

f. Twenty times

Figure 8. The deformation and temperature cloud chart of the bimetallic clad tube with defects under different compression and depressurization times. 
Nevertheless, if there is no defects in the liner, the instable deformation will not occur. It is mainly contributed to that there is no appearance of negative pressure in the inside of the liner in the depressurization process. Therefore, in the compression process, the substrate and liner is always firmly attached to the substrate which is displayed in Figure 9.

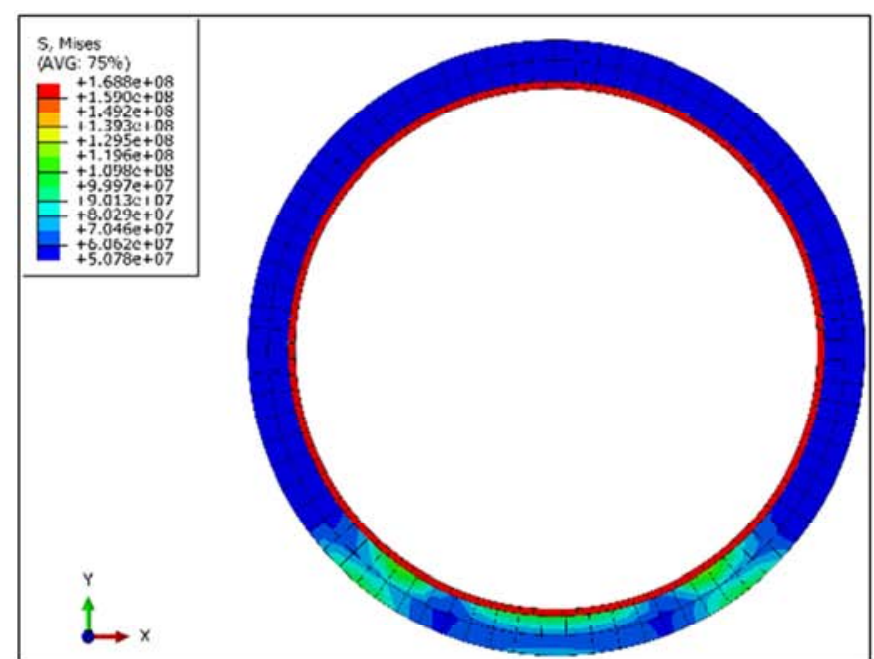

a. Once

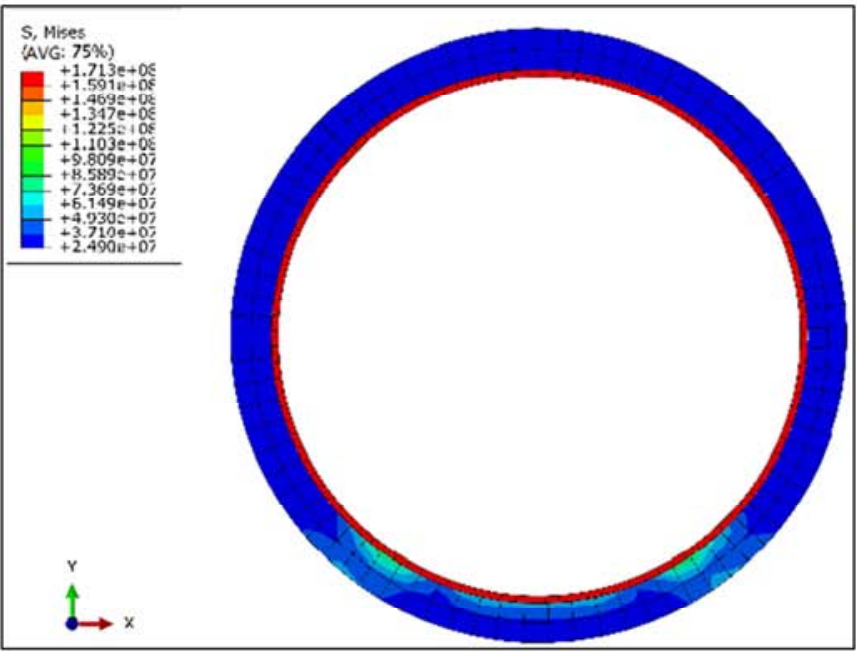

c. Five times

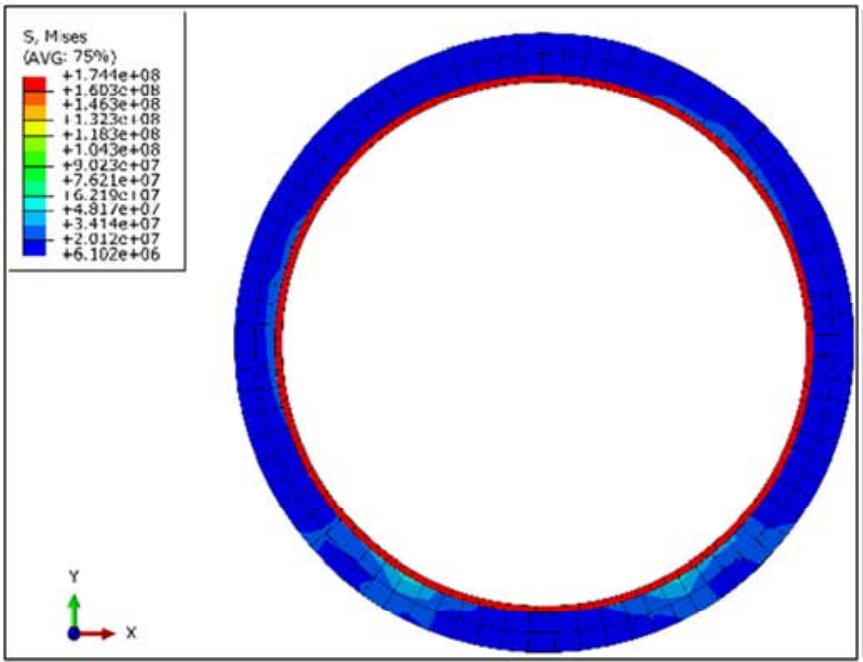

e. Fifteen times

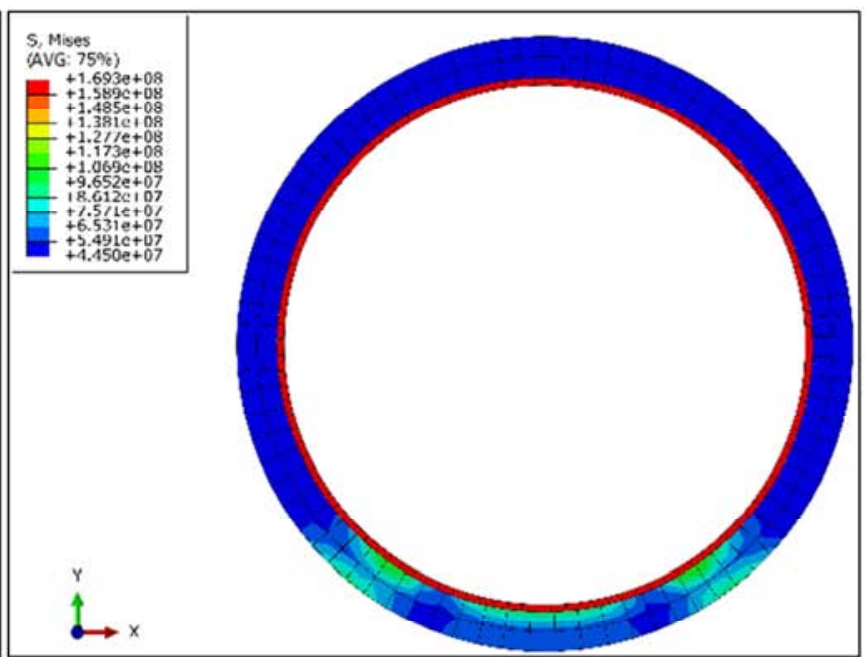

b. Twice

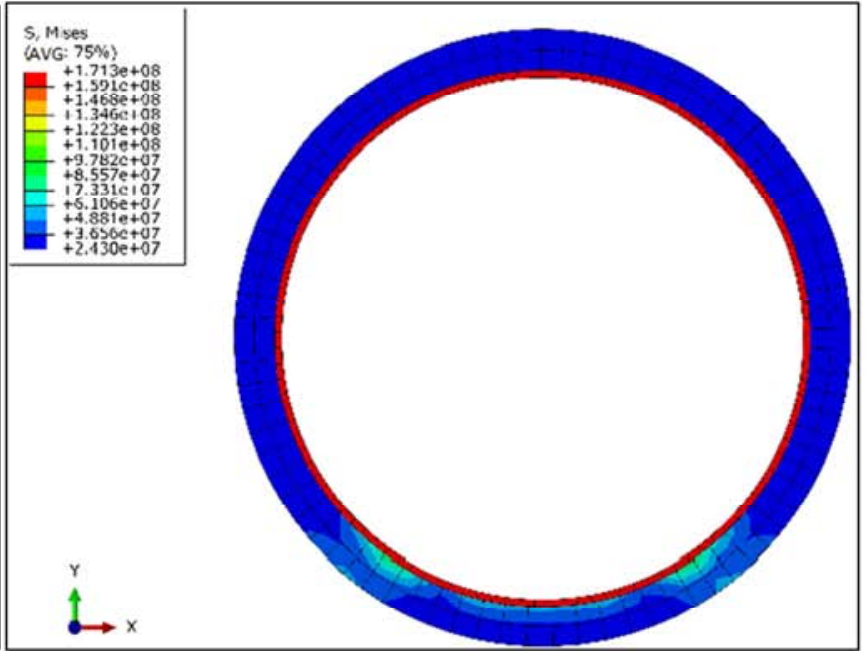

d. Ten times

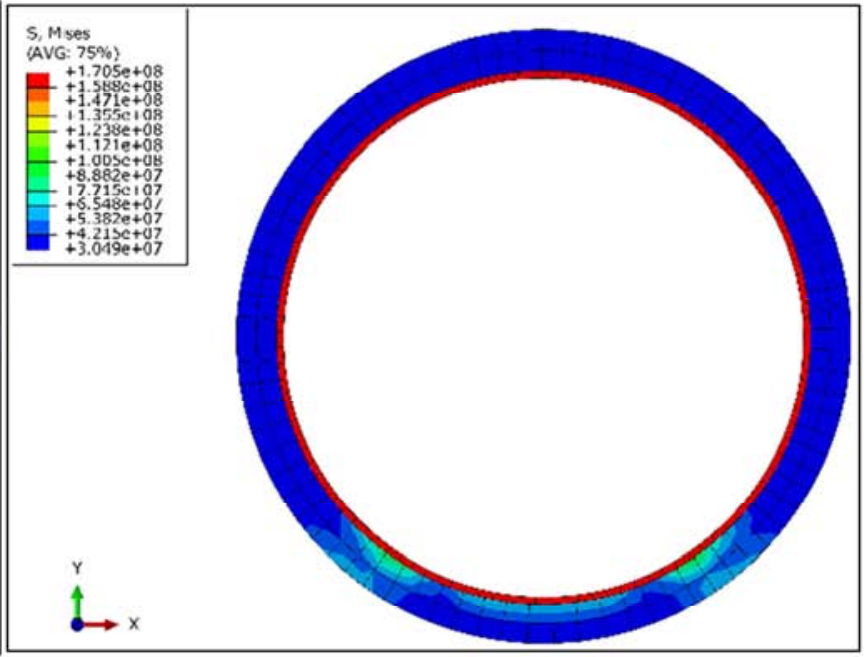

f. Twenty times

Figure 9. The deformation and temperature cloud chart of the bimetallic clad tube without defects under different compression and depressurization times. 


\section{Comparison and Analysis}

Figure 10 is the real bimetallic clad tube used in the practical manufacture process. Apparently, permanent plastic deformation has occurred in the liner. No matter the location or the shape of the plastic deformation is almost the same as the simulation result. In addition, the coefficients of thermal expansion of both the substrate and liner are tested. The results are shown in Figure 11 and Figure 12. When the tube is heated to $200^{\circ} \mathrm{C}$, the coefficient of thermal expansion of the substrate is $12.4685^{*} 10^{-6} / \mathrm{K}$, while the coefficient of thermal expansion of the liner is $18.6008 * 10^{-6} / \mathrm{K}$. When the temperature is lowered to $100^{\circ} \mathrm{C}$ which is also the practical service temperature, the coefficient of thermal expansion of the liner is almost twice that of the substrate, one is $16.7900 * 10^{-6} / \mathrm{K}$, the other is $9.0204 * 10^{-6} / \mathrm{K}$. Thus it can be seen that great difference of deformation will occur between the substrate and the liner because of the difference of the coefficient of thermal expansion resulting in the instable deformation of the liner which is also accordance with the simulation results.

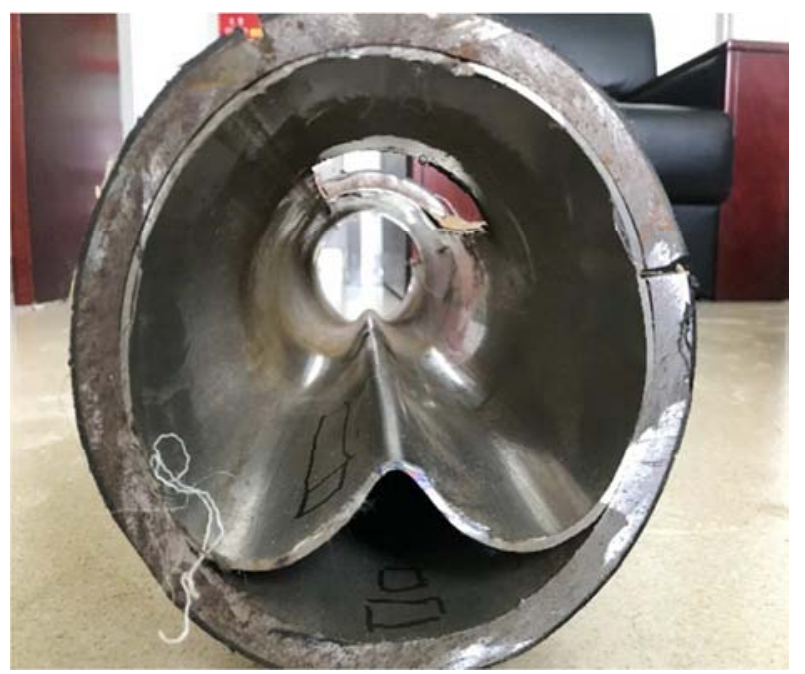

Figure 10. The deformation of the bimetallic clad tube in the practical manufacture process.

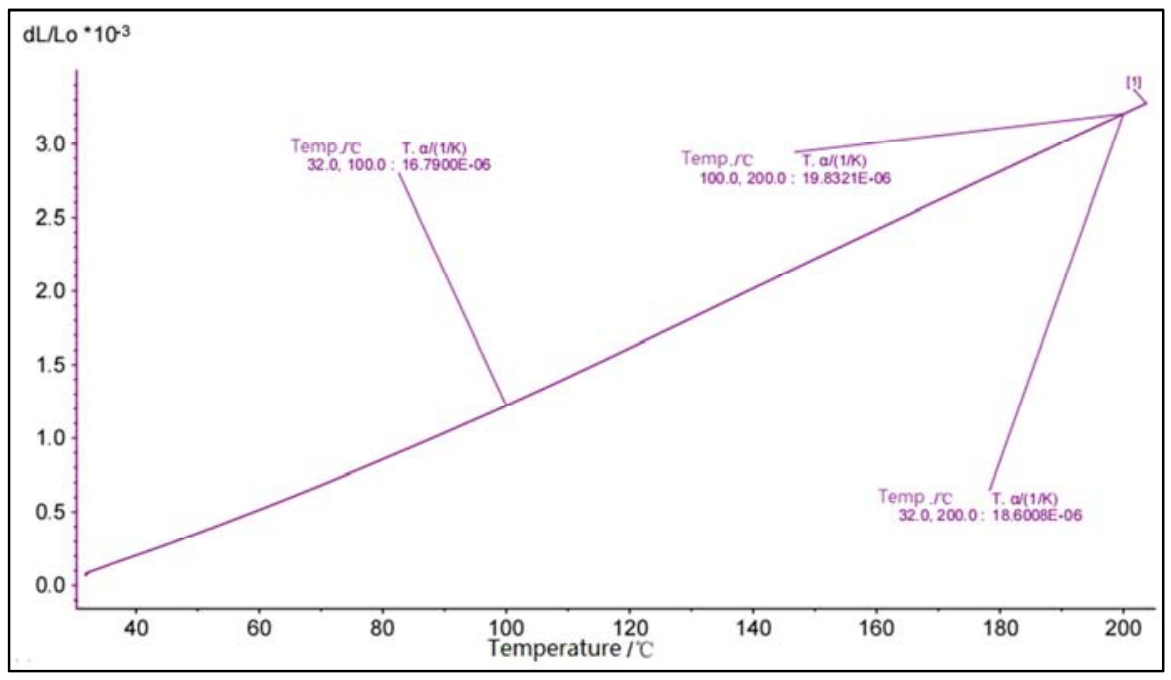

Figure 11. The thermal expansion curve of the liner.

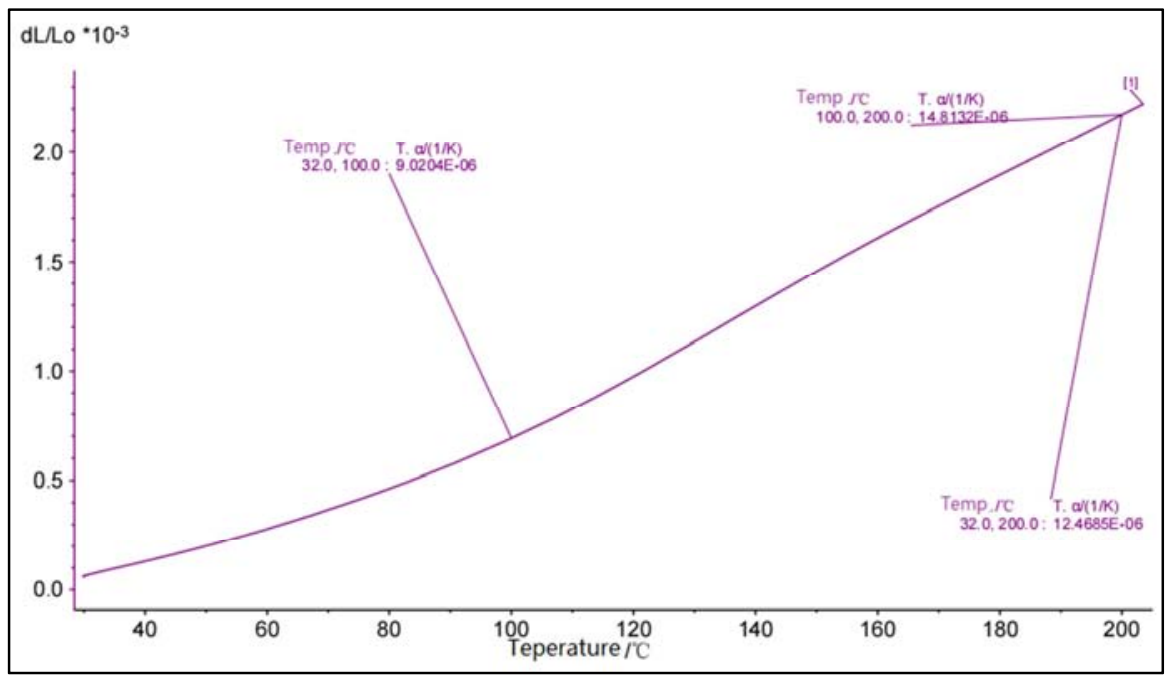

Figure 12. The thermal expansion curve of the substrate. 


\section{Conclusion}

The stability of the L245/316L bimetallic clad tube liner is greatly affected by the coating temperature and defects in the tube. Under high coating temperature of $230^{\circ} \mathrm{C}$, because of the combining effects of thermal expansion and contraction, residual stress and external constraint, the process can result in the instability deformation of the liner. Besides, if there are defects between the liner and substrate, the pressure during the compression and depressurization process can also lead to the instable deformation of the liner. Compared with the practical manufacture process, the simulation results are also accordance with the practical deformation.

\section{References}

[1] Chen Ke, Xu Wenbin, Lu Xiaofeng. Numerical simulation and analysis on spinning of 20/316Lbimetallic clad tube [J]. Journal of Plasticity Engineering. 2015, 22: 119-125.

[2] Khosravifard A, Ebrahimi R. Investigation of parameters affecting interface strength in $\mathrm{Al} / \mathrm{Cu}$ clad bimetal rod extrusion process [J]. Journal of Materials and Design. 2010, 31: 493-499.

[3] Guo Xunzhong, Tao Jie, Tang Xiaosheng. Cold push-bending simulation and experiment on TAl-Al bimetallic clad tube [J] The Chinese Journal of Nonferrous Metals. 2012, 22 (4): 1053-1062.

[4] Chen Haiyun, Cao Zhixi. Application and Development of Plastic Forming Technique for Double Metal Combined Pipe [J]. PROCESS EQU IPMENT\&PIPING. 2006, 43 (5): $16-18+21$

[5] T. Flatley, T. Thursfield. Review of corrosion resistant co-extruded tube development for power boilers [J]. Journal of Materials for Energy Systems. 1986, 8 (1): 92-105.
[6] Kyriakide S, Ju G T. Bifurcation and localization instabilities in cylindricall shells under bending - I experiments [J]. International Journal of Solids and Structures. 1992, 29 (9): $1117-1142$.

[7] Alcaraz J L, Gill-Sevillano J G. An analysis of the extrusion of bimetallic tubes by numerical simulation [J]. Int. J. Mech. Sci., 1996, 38 (2): 157-173.

[8] Berski S, Dyja H, Maranda A. Analysis of quality of bimetallic rod after extrusion process [J]. Journal of Materials Processing Technology, 2016, 177: 582-586.

[9] Mohebi M S, Abarzadeh A. A novel spin-bonding process for manufacturing multilayered clad tubes [J]. Journal of Materials Processing Technology, 2010, 210: 510-517.

[10] Mohebi M S, Abarzadeh A. Experimental study and FEM analysis of redundant strains in flow forming of tubes [J]. Journal of Materials Processing Technology, 2010, 210: 389-395.

[11] Rimma L K, Hoi P N. Bimetallic copper aluminium tube by severe plastic deformation [J]. Scripta Materialia, 2012, 66: 1081-1084.

[12] Du Yanmei, Wang Kaikun, Zhang Peng, etc. FEM simulation on extrusion of double-layer tube of aluminum and magnesium alloys [J]. The Chinese Journal of Nonferrous Metals. 2009, 19 (2): $208-216$.

[13] Yaghi A, Hyde T H, Becker A A, Sun W, Williams J A. Residual stress simulation in thin and thick-walled stainless steel pipe welds including pipe diameter effects [J]. International Journal of Pressure Vessels and Piping. 2006, 83 (11): 864-874.

[14] Al-Qureshi H A. Elastic-plastic analysis of tube bending [J]. International Journal of Machine Tools and Manufacture. 1999, 39 (1): 87-104. 